Alberto Arce, Negotiating agricultural development : Entanglements of bureaucrats and rural producers in Western Mexico (Wageningen Studies in Sociology. 34), Wageningen : Agricultural University 1993.ISBN 9047-54-283-0 ; 187 pp.

Thomas Bierschenk

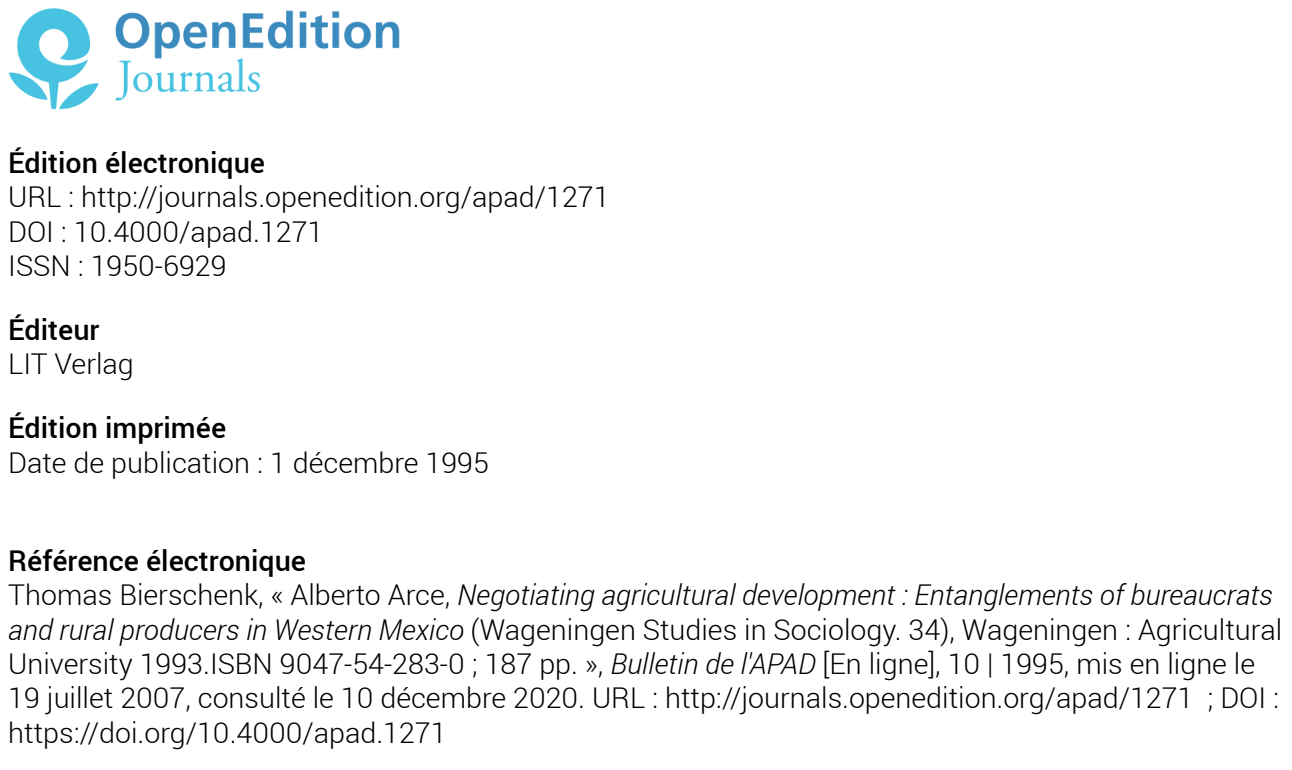

Ce document a été généré automatiquement le 10 décembre 2020.

Bulletin de l'APAD 


\title{
Alberto Arce, Negotiating agricultural development : Entanglements of bureaucrats and rural producers in Western Mexico (Wageningen Studies in Sociology. 34), Wageningen : Agricultural University 1993.ISBN 9047-54-283-0 ; 187 pp.
}

\author{
Thomas Bierschenk
}

Development aid projects are not simply a matter of the mechanical implementation of predefined programmes. They involve a permanent process of negotiation between actors who often represent very different interests, strategies and "life worlds". They are the prototype of a social and cultural "interface" and should, therefore, be se en as privileged places for anthropological observation and analysis, given that cultural difference has been the main focus of interest since the establishment of this discipline. These are the two main premises which form the basis of the theoretical programme disseminated in recent years by the Wageningen sociologists who work with Norman Long. Their published output in support of these ideas includes programmatic statements by Long himself and short empirical case studies by his Wageningen colleagues ${ }^{1}$.

2 The significance of Alberto Arce's study lies firstly in the way in which it attempts to apply this programme in an empirical study of book length. Moreover, while a number of studies are already available which adopt a local perspective (and which do not, by the way, all originate from Wageningen, something which is often overlooked there), Arce sets himself the ambitious goal of analysing state intervention in agriculture at and beyond local level; he changes perspective several times during his presentation 
and observes Mexican agricultural policy on the levels of the various ministries involved (chapter 2), from the perspective of a local office of the agricultural ministry (chapter 3), on the level of the agricultural extension agents (chapter 4) and also in two rural communities (eijido) (chapters 6 and 7). The administrative levels below the ministry are not straight forward executive instances. Arce presents them as social interfaces where agricultural policy represents an object of continuous negotiation for various social actors. This policy is transformed at these interfaces in accordance with the interests, strategies and "life worlds" of the actors involved long before it ever "reaches" the farmer. Thus, an "actorcentred" perspective is a prerequisite of any understanding of this transformation another of the Wageningen tenets shared by Arce.

3 This approach is most convincing in Arcets study where he deals with the local arenas in development, i.e. in chapters 6 and 7, the strongest chapters in the book. In chapter 6 Arce shows that interventions in local agricultural policy always come up against a network of socio-economic structures and power relations which in turn reflect local history and previous state intervention.

This leads, among other things, to individual groups of agricultural producers becoming clients of different state services. The historical dynamism of local social conflicts largely dictates the fate of state development programmes and these in turn deepen local divisions. Chapter 7 deals with an integrated agricultural development aid project as an arena of political conflict ; the project in question was implemented in the 1970 's by the Mexican government with the help of Hungarian technical experts. The analysis focuses on the interests, collective representations and rationalities behind the actions of the individual strategic groups of actors (Mexican politicians and bureaucrats, employees of an agricultural bank, Hungarian experts, various pressure groups among the rural producers) and the resulting complex lines of alliance and conflict which constituted the "social life" of the project.

5 Arce is, however, less successful in 'his attempt to integrate this local analysis into an ethnography of state action at super-local level. To start with, there is a problem with the way in which he structures his presentation. The author begins with the history of the reorganisation of Mexican agricultural administration in the 1970's and the reorientation of agricultural policy (under the heading "Mexican Food Policy/SAM") in chapter 2. This account is then interrupted by an ethnography of a local office of the agricultural ministry (chapter 3), and is resumed in Chapter 4. This awkward structure results in too many repetitions and puts unnecessary obstacles in the way of the reader's comprehension.

6 What these chapters mainly serve to show are the limits of this "actor-centred approach" as adopted by Arce. In the 1960's and 1970's, Mexican agricultural policy moved away from an exclusive concern with land reform and distribution and export-oriented irrigation agriculture in favour of the promotion of food production through rainwater cultivation. Parallel to this, the agricultural administration was reorganised and given a largely uniform structure. Bitter conflict subsequently arose within the new structure between the irrigation engineers, who had hit her to determined agricultural policy, and a new, emerging group of academically trained agronomists who represented a modem, efficiency-oriented extension approach. It is possible to glean some information about the structural background to this development from Arce's presentation : the main condition for the increased focus on 
food production would appear to be the expansion of Mexican oil production which resulted in the relative loss in significance of foreign currency income from agricultural exports and the simultaneous availability of agricultural subsidies. The increase in local maize production was also seen as desirable for foreign policy reasons as it meant a reduction in the country's dependency on supplies from the USA. Arce does in fact refer to this structural background but gives far greater emphasis to the activities of the Mexican president L. Portillo and an enlightened administrative reformer (A.J. Carillo Castro). Here, the "actor-centred approach" slips into a conventional account of great men who make history. This is followed by an account of the career of an agricultural official who belongs to the extension-oriented group of agronomists which adds a certain colour to the general statements made in this chapter. In end effect, however, this section is purely illustrative and does not add anything substantially new to the previous statements.

7 Arce's use of biographies in the two subsequent chapters, chapters 3 and 4 , is also problematic. Unlike chapters 6 and 7, where he focuses on the social relationships between the individual actors, no links are established between the actors in chapters 2 to 4 . Arce does not, as he purports to do, act as an ethnographer pursuing his actors through a series of social situations. The individual actors turn up at some stage in the text, give an account of their careers and are then banished by their author without further explanation. This can hardly be described as "situational analysis" and would appear to be far more a case of - to stick with Gluckmants terminology - "apt illustration". Moreover, a striking feature of this presentation is the way in which Arce's interviewees all come from the same side (the agronomists); the group of extension agents presented is even more selective in sociological terms- as they had all only worked in the ministry for a short time and told the researcher that they had been sent to less attractive posts in the provinces due to a lack of political contacts. Thus, the only account we get of the internal bureaucratic power struggles is from their perspective - i.e. from that of the losers. The "multiple perspectives analysis" which the author aims to provide would have necessitated versions of the story from other groups of actors. And despite the frequent use of the concept, we actually hear very little about the "life world" of the bureaucrats mentioned in the text as the presentation is largely restricted to the relevant career paths (in the form in which it is reconstructed by the actor for the researcher) and ethnographic observations of administrative culture. The criteria according to which the relevant interviewees (and units studied) are selected remain as unclear as the nature of the relationship between the interviewees and the researcher. Here, as is the case almost throughout the book (with the exceptions of chapters 4 and 7), Arce remains largely silent on the subject of his role in the field and his research methods. (For example, he fails to tell us whether the actors' career histories are literal accounts of long monologues or protocols from memory.)

8 As already remarked in reference to the concept of "life world", Arce's use of the heavy theoretical and conceptual artillery which he directs at his Mexican farmers and bureaucrats is not always convincing. I honestly have difficulties following some of the definitions, for example that which Arce gives of the "speech act" : "a feature of the actors' ability to connect, in action at the interface, speech, meaning, knowledge and performance" (p. 84). On the basis of the information which follows this definition, I assume that what is meant here are quite simply the different attitudes (authoritarian, paternal or egalitarian) of extension agents vis à vis the farmers. (However, more proof 
of their links with different social origins (rancher families, urban middle class or humble urban / rural background) would have been desirable. Arce often comes perilously close to reifying concepts (and tautology), for example when he writes that "actions depend on the agency of actors" (p. 169), "the process of reflexivity of such fieldworkers leads them to believe ..." (p. 95), "their reflexivity of policy implementation becomes entangled with their cultural attitudes ..." (p. 96) and he even becomes entangled in his own metaphors on occasion as when he writes that "(emerging) properties set in motion a battlefield" (p. 96).

9 This criticism is not intended to undermine the significance of the approach developed by Arce and his Wageningen colleagues, an approach which is largely shared by this reviewer. Development projects, development programmes, planned development are not only a significant reality in most Third World countries but also a privileged place for anthropological, multi-perspective analysis. Thus, Arce's book is essential reading for this kind of development anthropology which is rooted in anthropological theory.

\section{NOTES}

1.Cf. N. Long (ed.) Encounters at the interface, Wageningen 1989 and N. Long \& A. Long (ed.) Battlefields of Knowledge, London 1992. 